\title{
SPECIAL ANNOUNCEMENT \\ Focus of Papers \\ Twenty-Second Annual Meeting of the Psychonomic Society
}

The Psychonomic Society wishes to encourage presentation at its annual meeting of papers dealing with the application of psychological science to real-world problems. The meetings will be held at the Philadelphia-Sheraton Hotel, 1725 Kennedy Boulevard, in Philadelphia, November 12-14, 1981. The Call for Papers has been mailed to Society members, and programs and hotel reservation forms will be mailed to them in the early fall. The Secretary-Treasurer, J. Bruce Overmier, at the Department of Psychology, University of Minnesota, Minneapolis, Minnesota 55455, or the Publications Office, 2904 Guadalupe Street, Austin, Texas 78705, may be contacted for further information. 